\title{
Essential Drugs Inadequacy is an Impediment to Utilization of Universal Health Coverage; the Case of Seme Sub-County in Kisumu County, Kenya
}

\section{Hellen $0^{1 *}$, Daniel $0^{1}$, David $0^{2}$, Dorice $0^{1}$, Marion $\mathrm{A}^{1}$, Marceline $\mathbf{0}^{1}$ and Raphael $\mathrm{A}^{1}$}

${ }^{1}$ Jaramogi Oginga Odinga University of Science and Technology, Bondo, Kenya

${ }^{2}$ In-depth Research Services, Institute of Health and Social Work, Nairobi, Kenya

*Corresponding author: Hellen Ojwang, Jaramogi Oginga Odinga University of Science and Technology, Bondo, Kenya, Email: ojwanghellen@yahoo.com

\section{Research Article \\ Volume 5 Issue 1}

Received Date: January 22, 2021

Published Date: April 07, 2021

DOI: $10.23880 /$ phoa- 16000178

\section{Abstract}

Introduction: Many countries have been putting more effort in Universal Health Coverage through strengthening health systems to provide affordable, safe and high quality care. The Kenya government prioritized attainment of Universal Health Coverage which aimed at cushioning citizens against out of pocket expenditure on health services, though faced with challenges of staffing and inadequate medical supplies for proper implementation.

Aim: This was a descriptive cross sectional study design which examined the factors influencing utilization of Universal Health Coverage utilization in Seme Sub County.

Subject and Methods: The study targeted both community members and health facility managers. The health facilities were stratified according to their levels of care and randomly selected. The catchment population was stratified by administrative locations and a proportionate sampling technique applied giving a computed sample size of 377 participants, determined by Fischer's formula. The descriptive statistics were organized and summarized using tables and charts, while logistic regression analysis determined relationship between variables.

Results: The study revealed that availability of essential drugs in health facilities contributed positively in utilization of UHC as the availability of drugs in health facility is 2.52 times more likely to make people solely use UHC $(\mathrm{OR}=2.52,95 \% \mathrm{CI}=1.36$ 4.69, $\mathrm{p}<0.05$ ).

Conclusion: Essential drugs have direct significant influence on utilization of UHC services by community members. Considerable progress will only to materialize through improved supply of adequate essential drugs and procurement of essential medical equipment in the government health facilities in Kisumu County.

Keywords: Universal Health Coverage; Medical Supplies; Utilization; Medical Equipment; Essential Drugs

\section{Introduction}

Universal Health Coverage refers to a state where everyone receive the health care services they need without suffering financial hardship [1]. It encompasses all stages of service delivery from health promotion to prevention, treatment, rehabilitation, and palliative care [2]. In the year 2010 the Government of Kenya embarked on a reform of health policies, legislation and institutions where a thought to roll out Universal health Coverage was agreed upon [3]. 
UHC enables everyone to acquire all the services that address the most critical causes of disease and death, and ensures that the quality of those services is good enough to improve the health of the people who receive them [4]. Protecting people from the financial consequences of paying for health services out of their own pockets reduces the risk of people being pushed into poverty because unexpected health emergencies requires them to use all their savings and even get into borrowing; destroying their development plans and those of their children [5].

A report recently released by WHO in the year 2019 anticipated that despite the progresses made in Universal Health Coverage (UHC), as many as 5 billion people will be lacking access to healthcare in 2030 considering the current rate UHC is progressing globally, and financial protections that prevent families from ruinous health expenditure have been eroded in many countries. This makes households prone to suffering financial hardships despite the government's initiative to protect people from the financial consequences of paying for health services out of their own pockets and to reduce the risks that people will get into poverty due to unforeseen health challenges [6].

Vision 2030 considers health as an important foundation in improvement of life quality of Kenyan community. This is well stated in the Vision's health sector goal of ensuring an efficient expansion and affordable quality health care to all citizens [7]. Universal Health Care coverage for all is one of the Kenya's big four agenda targeting achievement of $100 \%$ coverage. This is realizable only through policy and administrative adjustments in the major institutions of the health care sector [8]. It is recommended that health being a devolved function in Kenya, a close collaboration between the Ministry of Health and the County governments and the private sectors be put into practice to enable transformation and achievement of Universal Health Care [7].

Millions of people still lack full access to basic health care services and this motivates attention being paid to ensuring availing measures of making health care affordable [8]. At the same time, the high costs associated with use of health services make many households experience unexpected financial burden [9]. Global estimates show that every year, approximately 150 million people experience huge health expenditure and out-of-pocket payments for health care services consume a larger proportion of their income that forces them to forego basic needs while 100 million are pushed into poverty because of health emergencies [4].

In African counties, financial protection is generally considered low requiring most patients to pay for health services from their own pockets, so-called out-of-pocket payments [10]. Patients in low income and lower middle income countries are less protected against high OOP than those from developed countries [11]. As a result of this, 11 million Africans are pushed into poverty every year due to high out-of-pocket expenditure. Protecting people against the distorting effect of huge health expenses is a cornerstone of UHC and will help in reduction of poverty in Africa [12]. Shortage of drugs has become too common and affects all levels of the health care delivery system. The increased number of drug shortages has also impacted negatively on patient care as well as costly financial implications [13].

World Health Organization defines Essential medicines as those that can fully respond to priority health needs of a specific population. Counties are guided by WHO Model List of Essential Medicines to develop their national and institutional essential medicine lists [14]. The guidance does not only allow countries to select medicines for their own context, but it has led to the global acceptance of essential medicines as a powerful means of promoting health equity, pursuing universal health coverage and strengthening health systems[15]. Essential medicines should be available to the patients at all times in adequate amounts, in appropriate dosages, and more so affordable. The drugs must be of acceptable quality and safe for use [16].

The main goal of Universal health coverage (UHC) is to ensure that everyone obtain the health services they need without suffering financial hardship when paying for the services. This is based on ensuring affordability of health care from preventive to curative and rehabilitative services for which essential health system resources are required. These resources include knowledgeable health workers, essential medicines and equipment. According to World Health Report 2010, Universal health coverage has been the main focus of the ongoing high-level discussions, a momentum and a pathway to which many agencies and governments put priorities [17].

Essential medicines remain a core requirement in implementation of quality care; they are an indispensable element for delivery of services and are also a requirement for high-quality care. Proper consideration must be given to ensuring reliability in access to quality assured essential medicines when designing benefit packages [18]. The health policy instruments that contribute to the effectiveness of the concept of essential medicines are; the National Essential Medicines Lists, formularies, standard treatment guidelines and measures to ensure access to affordable quality essential medicines [19].

\section{Materials and Methods}

This was a descriptive cross sectional study design on factors influencing utilization of UHC in Seme Sub County. 
The health facilities were stratified according to their levels of care and randomly sampled eight for the study. The catchment population was stratified by administrative locations and a proportionate sampling technique applied in each stratum giving a computed sample size of 377 participants, determined by Fischer's formula. Data collection was done by trained research assistants using semi structured questionnaires. The descriptive statistics were organized and summarized using tables and charts, while logistic regression analysis was used to determine relationship between variables. The ethical consent to carry out the study was sought from Jaramogi Oginga Odinga Teaching and Referral Hospital and Medical Officer of Health for Seme Sub County. The validity was ensured by Pretesting and retesting of questionnaires to determine their ability to address all the research questions, training of research assistants on how to carry out data collection and how to fill the data tools. The respondents were also briefed on the importance of giving the right information.

\section{Results}

The study on influence of Essential drugs and medical equipment on utilization of Universal health Coverage was conducted in Seme Sub County with proportionately sampled households and health facilities. The study targeted Community members who are registered under UHC and Health facility managers from sampled health facilities. The response was at $100 \%$ that is 377 households' representatives and 8 health facility managers. The descriptive statistics have been computed and summarized in charts and tables. Logistic regression examined the influence of essential drugs and medical equipment on Utilization of UHC. The findings were complemented by a checklist conducted in the sampled health facilities.

\section{Socio-Demographic Characteristics of the Community Members}

According to the results in Table 1, the distribution of the population by gender shows that majority of the community respondents were female $216(57.29 \%)$ and male were $161(42.71 \%)$. With respect to age, $39(10.35 \%)$ of the 377 sampled population were between 18 to 25 years old; majority of the respondents were $147(38.99 \%)$ aged between 26 years old and 35 years; $107(28.38 \%)$ were aged between 36 years and 45 years and $84(22.28 \%)$ were 46 years and above. With regards to education attainment, $4(1.06 \%)$ out of 376 community members who responded had no formal education; $90(23.94 \%)$ had primary education; majority of the respondents $200(53.19 \%)$ had secondary as the highest level of education and $82(21.81 \%)$ attained college. The results also illustrates that out of 377 respondents, $69(18.3 \%)$ were single; majority of the respondents $270(71.62 \%)$ were married; $30(7.96 \%)$ were widows and only $8(2.12 \%)$ were divorced. In relation to occupation, majority $269(71.35 \%)$ of the respondents were employed in informal sectors; $89(23.61 \%)$ were employed in formal sectors and $13(3.45 \%)$ were students. However, $6(1.59 \%)$ out of 377 respondents were unemployed. The distribution of the respondents by monthly income reveals that out of 361 respondents, 27(7.48\%) were earning less than 23 USD; majority $122(33.80 \%)$ were earning between 23 USD and 46 USD; 80 (22.16\%) of the respondents were earning between 47 USD and 70 USD; $40(11.08 \%)$ of the 361 respondents were earning between 71 USD and 92 USD and 92(25.48\%) were earning above 92 USD.

\begin{tabular}{|c|c|c|}
\hline Variables & Frequency (n) & Percentage (\%) \\
\hline \multicolumn{3}{|c|}{ Gender $(\mathrm{N}=377)$} \\
\hline Male & 161 & 42.71 \\
\hline Female & 216 & 57.29 \\
\hline \multicolumn{3}{|c|}{ Age $(\mathrm{N}=377)$} \\
\hline 18 to 25 & 39 & 10.35 \\
\hline 26 to 35 & 147 & 38.99 \\
\hline 36 to 45 & 107 & 28.38 \\
\hline 46 and above & 84 & 22.28 \\
\hline Mean(SD) & $37.46(10.86)$ & \\
\hline \multicolumn{3}{|c|}{ Level of education $(\mathrm{N}=376)$} \\
\hline None & 4 & 1.06 \\
\hline Primary & 90 & 23.94 \\
\hline Secondary & 200 & 53.19 \\
\hline College & 82 & 21.81 \\
\hline \multicolumn{3}{|c|}{ Marital status $(\mathrm{N}=377)$} \\
\hline Single & 69 & 18.3 \\
\hline Married & 270 & 71.62 \\
\hline Divorced & 8 & 2.12 \\
\hline Widowed & 30 & 7.96 \\
\hline \multicolumn{3}{|c|}{ Occupation $(\mathrm{N}=377)$} \\
\hline Formal employment & 89 & 23.61 \\
\hline Informal employment & 269 & 71.35 \\
\hline Unemployed & 6 & 1.59 \\
\hline Student & 13 & 3.45 \\
\hline \multicolumn{3}{|c|}{ Monthly Income in USD $(\mathrm{N}=361)$} \\
\hline $0-23$ & 27 & 7.48 \\
\hline $24-46$ & 122 & 33.8 \\
\hline $47-69$ & 80 & 22.16 \\
\hline $70-92$ & 40 & 11.08 \\
\hline Above 92 & 92 & 25.48 \\
\hline
\end{tabular}

Table 1: Socio-Demographic Characteristics of the Community Members. 


\section{Utilization of UHC}

Figure 1 Shows that out of the 377 community respondents, majority at 71\% (267) respondent used both UHC and private health facilities for health services, $27 \%$ solely used UHC while $2 \%$ never used UHC.

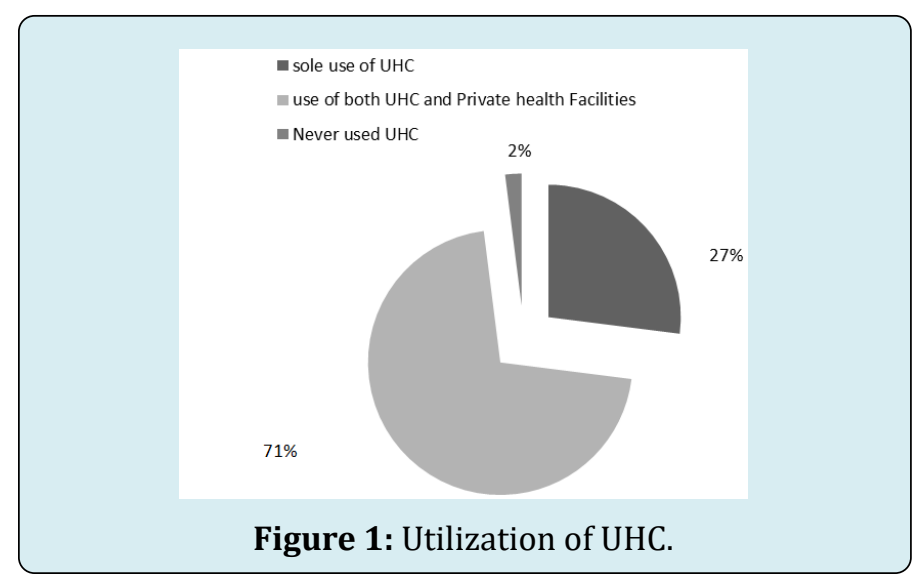

\section{Community Medical Expenses for the Past One Year in USD}

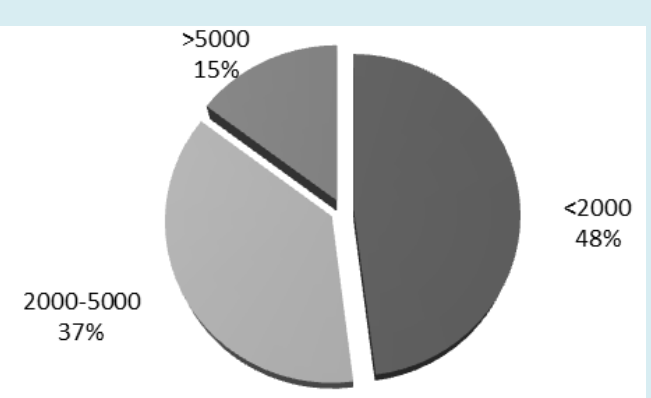

Figure 2: Community Medical Expenses for the Past One Year in Kenya shillings.
Figure 2 presents the medical expenses incurred by the community members after the launch of UHC in Kisumu County, 183 households (48\%) spent below 20 USD, and 139 households (37\%) spent between 21 USD to 46 USD while 55 households (15\%) spent more than 46 USD.

\section{Influence of Availability of Essential Drugs on UHC Utilization in Seme Sub County}

Table 2 presents multivariate logistic regression on the influence of availability of essential drugs on UHC utilization. Availability of prescribed drugs in a health facility was found to be a significant factor on utilization of UHC, $p<0.05$. From the results, the respondents who were getting all the prescribed drugs in the their link facility were 2.52 times more likely to solely used UHC as compared to those who were not getting all prescribed drugs $(\mathrm{OR}=2.52,95 \% \mathrm{CI}=1.36$ $4.69, \mathrm{p}<0.05$ ). With regards to drug shortage in the health facility, the results revealed that the shortage of drug supply has got a significant influence of UHC utilization in Seme Sub-County where drug shortage is 0.25 times less likely to make people to solely utilize their UHC as compared to drug availability (OR $=0.25,95 \% \mathrm{CI}=0.09-0.70, \mathrm{p}<0.05)$. The number of occasions in which a health facility experiences drug shortage was also found to be statistically significant, $p<0.05$. The respondents who experienced drug shortage in their health facilities once in a period of six months were 2.31 times more likely to solely use UHC as compared to those who experienced drug shortage more than twice (OR = $2.31,95 \% \mathrm{CI}=1.30-4.12, \mathrm{p}<0.05)$. The results further reveal that those who experience drug shortage twice in a period of six months were 1.82 times more likely to solely use UHC as compared to those who experienced drug shortage for more than twice within a period of six months $(\mathrm{OR}=1.82,95 \% \mathrm{CI}=$ $1.11-3.00, \mathrm{p}<0.05)$.

\begin{tabular}{|c|c|c|c|c|}
\hline Variables & $\mathbf{n}(\%)$ & Odds Ratio & p-value & 95\% CI \\
\hline \multicolumn{7}{|c|}{ Get all prescribed drugs } \\
\hline Yes & $52(13.79)$ & 2.52 & 0.003 & $1.36-4.69$ \\
\hline No & $325(86.21)$ & & & $0.09-0.70$ \\
\hline \multicolumn{7}{|c|}{ Drug shortage } & 0.08 & \\
\hline Yes & $355(94.16)$ & 0.25 & 0.004 & $1.30-4.12$ \\
\hline No & $22(5.84)$ & & 0.017 & $1.11-3.00$ \\
\hline \multicolumn{7}{|c|}{ Occasions of drug shortage } \\
\hline Once
\end{tabular}

Table 2: Multivariate Logistic Regression of the Influence of Availability of Drugs on the Utilization of UHC. 


\section{Drug Supply from Kenya Medical Supplies Authority (KEMSA)}

Figure 3 reveals that out of the 8 facility managers interviewed, majority $(62.50 \%)$ disagreed that there was adequate supply of drugs from KEMSA; 25\% of the managers strongly disagreed that they receive adequate drugs from KEMSA. No manager agreed that there was adequate supply of drug in their facility by KEMSA.

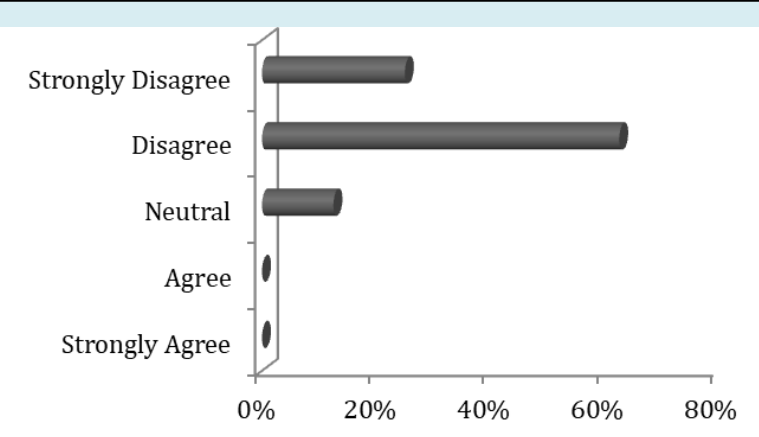

Figure 3: Adequacy Drug Supply from KEMSA.

\section{Drug Shortage in the Health Facilities}

As shown in Figure 4, majority (62.50\%) of managers strongly agreed that there was drug shortage in their facilities; $25 \%$ of the managers agreed that there was shortage of drugs in their stores and only $12.5 \%$ of the managers strongly disagreed that there was drug shortage in their respective health facilities.

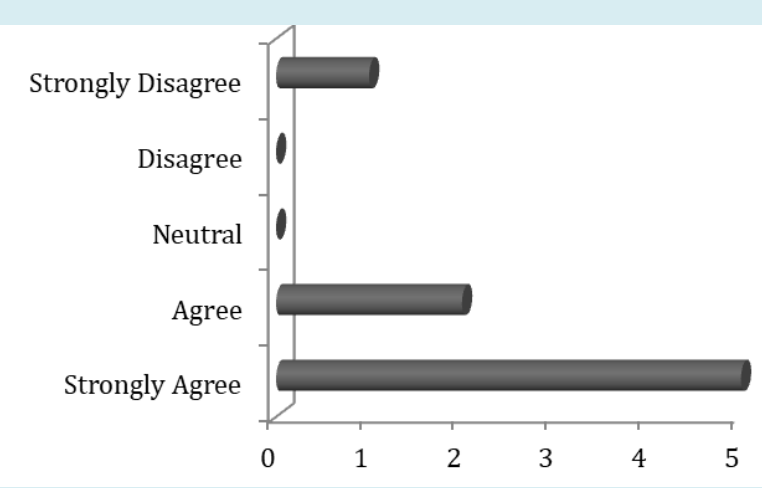

Figure 4: Drug Shortages in the Health Facilities.

\section{Discussion of Results}

This chapter shows how the significance of the findings of this study have been interpreted and described in light of the results of other studies reviewed in chapter two. It sheds lights on the new insights about the hindrance of utilization of universal Health Coverage in Seme Sub County in relation to influence by adequacy of essential drugs.

\section{Expenditure on Health Care Services by Community Members}

The study found out that 122(majority) household owners (33.80\%) were earning between Ksh 24 USD to 46 USD Again, 139 (majority) households (37\%) spent between 20 USD to 46 USD while 55 households (15\%) spent more than 46 USD on medical expenses. This is in agreement with a study done by WHO in 2016 which found out that globally every year, nearly 150 million people experience catastrophic health expenditure where household out-of-pocket payments for health care consume a larger proportion of their income that forces them to forego other goods and services while 100 million are pushed into poverty [4]. In view of the earning of the majority being less than 46 USD, and incurring medical expenses above 20 USD, the community members are prone to suffering financial hardship hence they will not be able to afford the family basic needs. The ruinous expenses will also affect the education of the children thus impacting negatively on economic growth of various families. A lot of emphasis needs to be put on implementation and enforcement of Healthcare Financing policy by dedicating more resources to health in support of the UHC agenda to improve its implementation and to ensure financial protection for all citizens.

\section{Availability of Essential Drugs for UHC Implementation}

In Kenya, ministry of health has undertaken several strategies that are aimed at facilitating the expansion of service delivery and affordability of health services by rolling Universal Health Coverage in urban and rural areas [20] However, this has not been successful due to inadequate supply of essential drugs in health facilities. Shortage of drugs and medical supplies is a challenge facing implementation of UHC. The study found that availability of essential drugs in health facilities contribute positively in utilization of UHC as the availability of drugs in health facility is 2.52 times more likely to make people solely use UHC (OR $=2.52,95 \% \mathrm{CI}=$ $1.36-4.69, \mathrm{p}<0.05)$. This is in agreement with a study done in China [21] which revealed that availability of medicine is positively associated with the implementation and uptake of Universal Health Coverage. It also concurs with a study done by kangwana BB, et al. [15] which found out that in Kenya, there is rampant drug shortage in health facilities which is causing delay in implementation of essential health Care services and that lack of drugs in many public health facilities compels citizens to seek medical care in private hospitals. Reasons for the high frequency of drug shortage reflect the problems facing weak health systems like procurement problems and stock management. The clients who are not able to afford the drugs due to their low income are prone to deterioration in their health status and even die from such 


\section{Public Health Open Access}

minor ailments which would have been managed if they got drugs from the government health facilities at affordable costs. Access to essential medicine being a core component of the right to health and also a requisite to attainment of UHC, more attention needs to be put on drug supply to the counties in relation to their demands.

Our study confirmed that implementation of UHC is blocked by inadequate essential medical equipment for diagnosis and treatment of diseases as majority (> 50\%) of the facility managers agreed that there is not enough medical equipment in their facilities. Lack and non-functionality of essential medical equipment in various government health facilities motivated the community member to seek diagnostic and other specialized care from the private hospitals where they were forced to spend a lot of money from their pockets. Some health facilities managed the patients clinically using the symptoms without confirmation of the disease conditions; hence some do not recover while others develop complications from misdiagnosis.

\section{Conclusion}

Evidences show the challenges surrounding UHC implementation leading to reduced utilization and making the community members prone to financial hardship as they pay for health expenses. Evidences show that inadequacy of essential drugs in the government health facilities influenced utilization of UHC and promoted out of pocket expenditure by the community members.

\section{Recommendation}

In order to improve utilization of Universal Health Coverage in Seme Sub County and other sub Counties in Kisumu County, the County government of Kisumu and the national government need to facilitate supply of adequate essential drugs in all government health facilities.

\section{Acknowledgement}

- The Medical Officer of Health (Seme Sub County) for administrative Support

- The Ward Public Health Officers for data Collection

- Respondents for accepting to participate in the study

\section{Conflict of Interest}

The authors have no any conflict of interest.

\section{Funding}

The Authors did not receive any grant for the study. The expenses for the study were funded by the Corresponded
Author Mrs. Hellen Ojwang.

\section{Ethical Approval}

Ethical approval was obtained from Jaramogi Oginga Odinga Teaching and Referral Hospital ERC and a study permit from National Commission for Science, Technology and innovation (NACOSTI).

\section{Informed Consent}

A written consent was obtained from both the Health facility managers and the community members before starting the study.

\section{References}

1. WHO (2015) Health in 2015: From Millennium Development Goals to Sustainable Development Goals, Geneva.

2. Faizi N, Kazmi S (2017) Universal health coverage - There is more to it than meets the eye. J Family Med Prim Care 6(1): 169-170.

3. Barasa E, Rogo K, Mwaura N, Chuma J (2018b) Kenya National Hospital Insurance Fund Reforms: Implications and Lessons for Universal Health Coverage. Health Syst Reform 4(4): 346-361.

4. Beattie A, Yates R, Noble DJ (2016) Accelerating progress towards universal health coverage in Asia and Pacific: improving the future for women and children. BMJ Glob Health 1(S2): i12-i18.

5. Lauer JA, Rajan D, Bertram MY (2017) Priority Setting for Universal Health Coverage: We Need to Focus Both on Substance and on Process Comment on Priority Setting for Universal Health Coverage: We Need EvidenceInformed Deliberative Processes, not Just More Evidence on Cost-Effectiveness. Int J Health Policy Manag 6(10): 601-603.

6. Ozumba BC, Onyeneho NG, Chalupowski M, Subramanian SV (2019) Inequities in Access to Maternal Health Care in Enugu State: Implications for Universal Health Coverage to Meet Vision 2030 in Nigeria. Int Q Community Health Educ 39(3): 163-173.

7. Okech TC, Lelegwe SL (2015) Analysis of Universal Health Coverage and Equity on Health Care in Kenya. Glob J Health Sci 8(7): 218-227.

8. Obare V, Brolan CE, Hill PS (2014) Indicators for Universal Health Coverage: can Kenya comply with the proposed post-2015 monitoring recommendations? Int 
J Equity Health 13: 123.

9. Butler K, Larney S, Day CA, Burns L (2019) Uptake of direct acting antiviral therapies for the treatment of hepatitis $\mathrm{C}$ virus among people who inject drugs in a universal health-care system. Drug Alcohol Rev 38(3): 264-269.

10. Barasa E, Nguhiu P, McIntyre D (2018a) Measuring progress towards Sustainable Development Goal 3.8 on universal health coverage in Kenya. BMJ Glob Health $3(3)$.

11. Lu C, Chin B, Lewandowski JL, Basinga P, Hirschhorn LR, et al. (2012) Towards universal health coverage: an evaluation of Rwanda Mutuelles in its first eight years. PLoS One 7(6).

12. Mimiko O (2017) Experiences with Universal Health Coverage of Maternal Health Care in Ondo State, Nigeria, 2009-2017. Afr J Reprod Health 21(3): 9-26.

13. Park HY, Hong YC, Kawachi I, Oh J (2018) Gaps in universal health coverage in South Korea: Association with depression onset in a community cohort. PLoS One 13(6).

14. Fukuda A, Igarashi A (2016) [Universal Health Coverage and Cancer Drugs-A Cost-Effectiveness Perspective]. Gan To Kagaku Ryoho 43(11): 1311-1315.
15. kangwana BB, Njogu J, Wasunna B, Kedenge SV, Memusi DN, et al. (2009) Malaria Drug Shrtage in kenya: a major failure to provide access to effective treatment. Am J Trop Med Hyg 80(5): 737-738.

16. Carlson J, Evans M (2010) No brakes. With healthcare's share of the GDP seeing record growth and government financing set to soon account for more than half of all health spending, providers renew call to overhaul the system. Mod Health 40(6): 6-7.

17. Friebel R, Molloy A, Leatherman S, Dixon J, Bauhoff S, et al. (2018) Achieving high-quality universal health coverage: a perspective from the National Health Service in England. BMJ Glob Health 3(6): e000944.

18. Mwangi CN (2019) Sustainability of Universal Health Coverage, The Case of Medical Supplies by Kenya Medical Supplies Authority.

19. Gupta V, Kerry VB, Goosby E, Yates R (2015) Politics and Universal Health Coverage-The Post-2015 Global Health Agenda. N Engl J Med 373(13): 1189-1192.

20. Luoma M, Doherty J, Muchiri S, Barasa T, Hofler K, et al. (2010) Kenya Health System assessment, Bethesda MD.

21. Huang Y, Jiang Y, Mao W, Luying Z, Van Boven JF, et al. (2018) Availability, Use and Affordability of Medicine in Urban China Under Universal Health Coverage. BMC Health Serv Res 18: 218. 